\title{
Assessing and Assisting Arab Undergraduates' Skills in Producing Research Papers in English
}

\author{
Ranwa Khorsheed \\ Arab International University, Damascus, Syria
}

\begin{abstract}
This paper discusses the results of a study conducted on a group of undergraduates at the Arab International University. The study has assessed the students' research skills via a qualitative analysis of their earlier research papers submissions and a questionnaire that determined the weaknesses and difficulties they face while writing a paper. Results showed that undergraduates find it most difficult to use and understand English references, paraphrase paragraphs and use in-text citations. Based on the quantitative and qualitative analysis of the results, the researcher devised a new course that aimed to enhance students' practice of the main research skills. This course was based on developing student's information literacy and assigning multiple focused tasks to practice the main research skills. The post course evaluation of students' achievement showed a notable improvement in their research practices that aided the production of above average quality English research papers.
\end{abstract}

Index Terms - research skills, information literacy, paraphrase, in-text citation

\section{INTRODUCTION}

Undergraduate research is an essential experience that equips students with the basic skills required for a successful academic journey. However, this experience is usually packed up into a single subject. Thus, undergraduates are required to make the most out of it by focusing on the development of their individual research skills.

\section{A. Digital Literacy}

Throughout the last decade, information literacy has been the focus of higher education. It is greatly recognized in the literature that assessment has become the core of all fields of higher education. Subsequently, according to Tancheva, Andrews, and Steinhart, "there has been a shift in emphasis from inputs and outputs ...to users and outcomes." Likewise, Oakleaf, Millet, and Kraus stress that information literacy, introduced by the Association of College \& Research Libraries (ACRL) as the competence to "recognize when information is needed and have the ability to locate, evaluate, and use effectively the needed information," is a critical aptitude in all academic fields. In 2012 , Schilling and Applegate clarify that, during the 1990s, advanced education certifying offices started to embrace data proficiency capabilities as markers of scholastic achievement, and the ACRL started building up the Information Literacy Competency Standards for Higher Education, exhibiting the developing spotlight on this imperative range of abilities. Oakleaf, Millet, and Kraus additionally report, notwithstanding, that graduates keep on showing immature data proficiency abilities, while overestimating their own capacities here. Along these lines, there has been a developing pattern, detailed in some of the articles investigated here, toward consolidating data proficiency skills into different scholarly teaches. Oakleaf and Kaske examine the expanding inclusion of custodians in the accreditation interaction through the exhibition of their commitment to the advancement of data education abilities and the creation of value graduates. The best methods for accomplishing this objective is through the application and announcing of value evaluation rehearses; yet, in a different 2008 article, Oakleaf defies the way that numerous bookkeepers feel illequipped to address this difficulty. Andone et al (2007), Gonzales (2010), Holt , Smissen and Segrave (2006) and Hannon (2009) perceive students as digitally oriented individuals due to their constant use of digital devices and stress the importance of cultivating their digital competence with proper guidance towards useful research practices.

The rise and headway of data innovation is the main factor influencing the insightful correspondence. This innovative progression assists with getting required data rapidly and without any problem. In this innovative period, the print medium is progressively offering path to the electronic type of materials (Sharma, 2009). The change from print to electronic medium separated from bringing about a development of electronic data, has given clients new apparatuses and applications for data chasing and recovery (Ani and Ahiauzu, 2008; Islam and Rahman, 2014). Henceforth, the libraries need to change from its traditional methodology of procurement, association and sharing of data, to current and mechanical driven methodologies. All things considered, numerous libraries have changed into computerized and virtual libraries, where books, diaries and magazines have changed into digital books, ejournals, and e-magazines. One of the capacity of the innovative driven and ICT based library administrations is to furnish the clients with promptly accessible online data assets. The online data assets are those which can be open through World Wide Web, for example, e-diaries, digital books, e-data sets, and online web crawlers; notwithstanding, it goes under the more extensive term of electronic assets. E-assets are the electronic portrayal of data which can be gotten to through electronic framework and 
PC organization (IFLA, 2012). Online data assets are priceless examination apparatuses that supplement the print-based assets and are getting increasingly more significant for the scholarly local area, these days (Egberongbe, 2011). Additionally, the most momentous and advantageous of online assets is that it underpins the analyst regardless of the time and topographical boundary. Despite the fact that the online assets are promptly accessible and speediest, they are still underutilized. There are number of elements contributing their underutilization. Absence of mindfulness and abilities with respect to the utilization of online assets is one of the significant obstructions. Skills identified with utilization of online assets are not just fundamental to recover the open access and membership based substance, yet in addition basic to achieve their scholarly and exploration needs. Watts and Ibegbulam (2006) brought up that the utilization of electronic data assets generally relies upon the client's capacity to explore the labyrinth of online assets accessible through innovation based terminals.

\section{B. Early Studies}

This research is formed following the trend of what is called educational research design. This kind of research basically depends on uncovering the human factors involved on the side of the students in acquiring and practicing academic research skills and on the side of the tutors whose role is to deliver, transfer, or share their research skills with the students depending on a (feedback-loop). This included a questionnaire distributed prior to the research instructional phases and a post instructional phase evaluation (Reeves, McKenny, \& Herrington, 2010; Collins, Joseph, \& Beilaczyc, 2004; Reeves, Herrington, \& Oliver, 2005).

Quarton (2003) and Maybee (2006), highlight the importance of regular exposure to research assignments, in which the students are required to access and explore information, look for answers, critically evaluate different sources and use the information effectively to accomplish their tasks. This supports the choice of the research assignments discussed in this paper as they were designed to be scaffolding in nature of students' investigation and metacognitive skills as they work in groups.

\section{METHODOLOGY}

\section{A. Pre-sessions Delivery}

Surveys are used as a measure of students' self-confidence, skills and behavior. The strength of surveys lies in their ease of administration and ease of scoring even though they focus on intention not behavior (Erlinger, 2018).

\section{B. Post-sessions}

Watson et al (2013) and Spackman (2007) depended on focus groups to collect feedback after information literacy sessions. The benefits of focus groups lie in the ability to clarify, ask, and collect data from several participants at once. Focus groups are facilitated structured open ended discussions with a group of participants on the process and skills. But they cannot measure learning as they are basically self-reports.

\section{Research Context}

This study was conducted at the Foreign Languages Center (FLC) at the Arab International University (AIU), Damascus, Syria. The FLC offers remedial English courses to improve undergraduates English language skills to help them follow up with their other English major related courses. The remedial courses include a course of academic writing and research (AWR). This course was devised to help students practice writing research papers in English following the APA rules. However, this course mainly required students to memorize the APA and exhibited no significant results with limited successful attempts by students to produce complete flawless original research papers. Thus, comes the importance of this study.

\section{Participants}

The students who participated in this study are a group of 52 undergraduates who have completed a level three remedial English course. Most of these students belong to the (19-23) age group. In addition, these students can be said to have simple to no research skills.

\section{E. Qualitative Analysis of Students' Earlier Paper Submissions}

A number of students' earlier paper submissions were analyzed. Analysis showed that most of these papers have a good amount of plagiarized sections. Sometimes whole original papers or even chapters of books were plagiarized, copied and presented as a student's submission for the end of the course work activity. In addition, some of the papers that exhibited signs of originality had some major flaws in planning, total organization, quoting, citing, and referencing. For example, in these papers students have mainly depended on their general knowledge of their paper's topic. Thus, they presented papers with poor content that lack the support of previously published books or articles on the same topic.

\section{RESUlTS AND ANALYSIS}


A questionnaire was conducted to determine students' main weaknesses and the difficulties they face while writing a research paper in English. The questionnaire is divided into five main parts. The first part used a three point Likert scale (easy, normal difficulty, hard) and had three sub-categories. Each category focused on a group of related research skills. The following diagram represents the difficulty percentages as stated by the students with relation to the first category of research skills that includes choosing a topic, writing research questions, brain storming, and generating an outline.

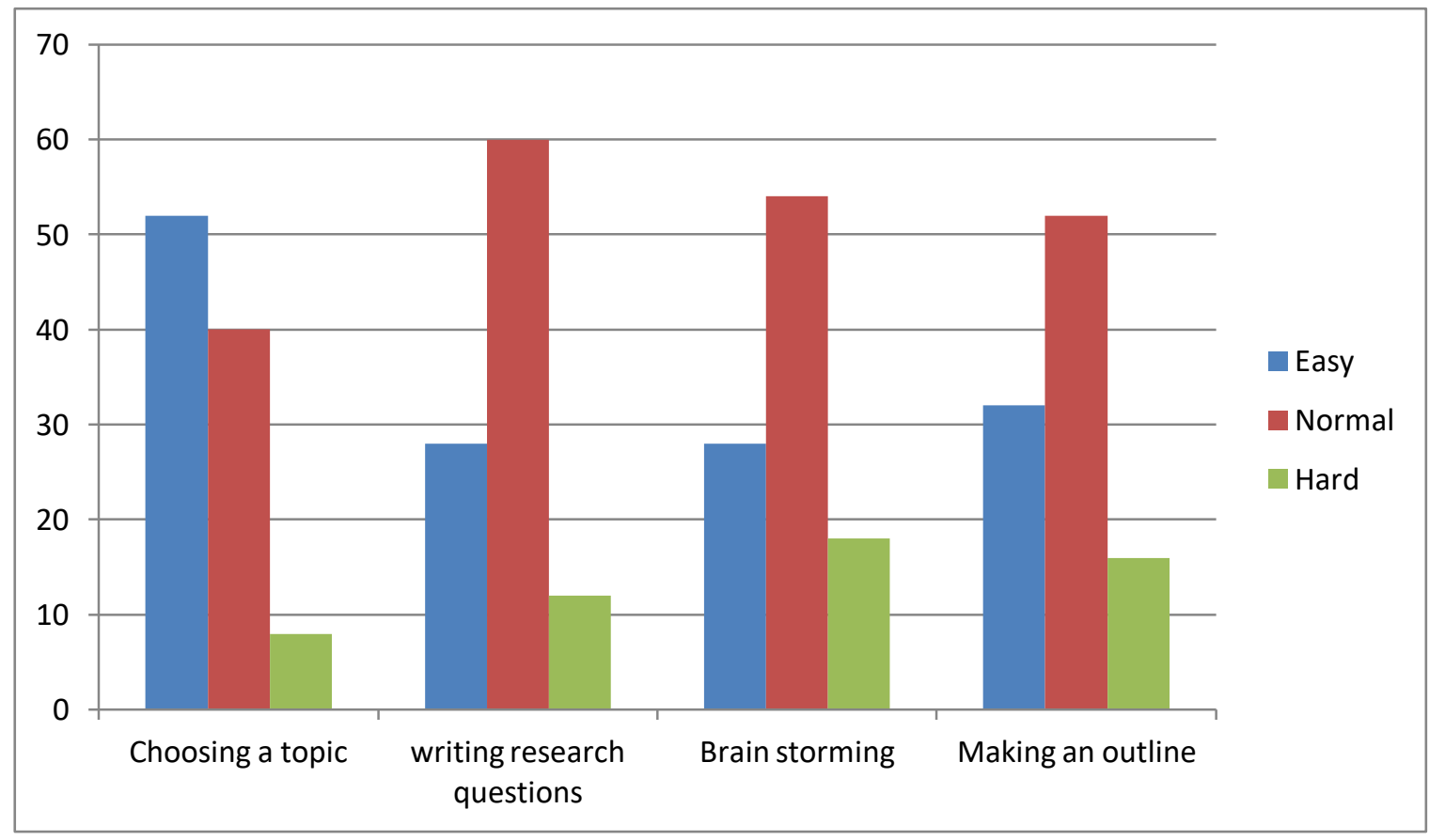

As shown in the previous diagram, $50 \%$ of the students find it easy to choose a topic for their paper. In addition, $60 \%$ of the students expressed a medium to normal difficulty in writing research questions, $54 \%$ brain storming and $52 \%$ generating an outline for their papers with the highest value for the skill of writing research questions.

The second category of research skills included the skills of finding suitable English references, reading and understanding English references, determining main ideas in the original English reference, paraphrasing original paragraphs, summarizing original paragraphs, and expressing personal opinions about the topic. The following diagram represents the different percentages of difficulty for each of the above mentioned skills.

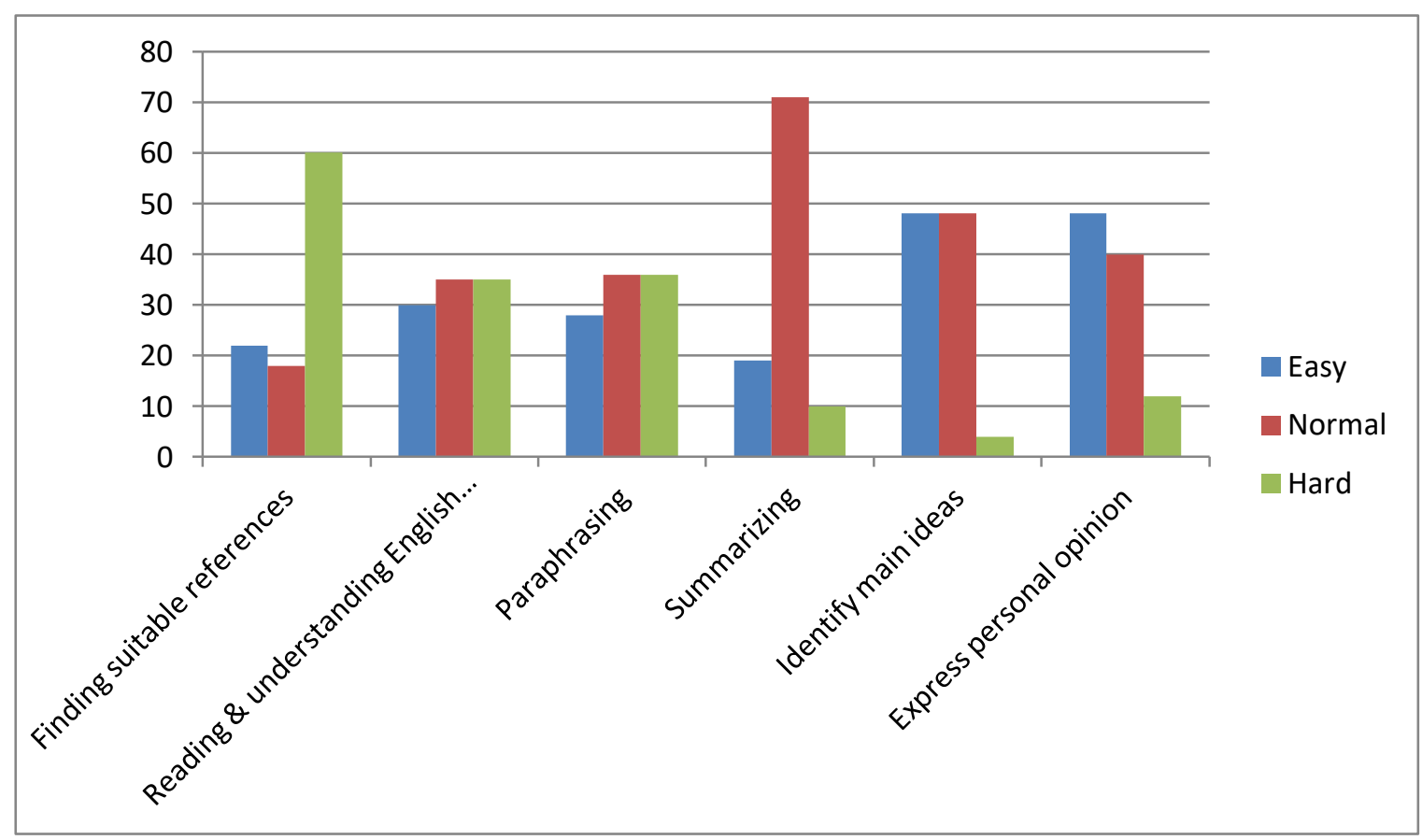


As shown in the diagram above, the most difficult skill for students to practice was finding suitable English references for their papers. However, it was also relatively difficult for students to summarize paragraphs of the original reference. On the other hand, the easiest skill was to express personal opinion about an issue or a topic. Furthermore, reading and paraphrasing English references were both of normal difficulty to students.

The third category of research skills included the skills of using quotations, using in-text citations, combining two references to support one idea, writing an abstract, and making a list of references. The following diagram shows percentages of difficulty for each of the aforementioned skills.

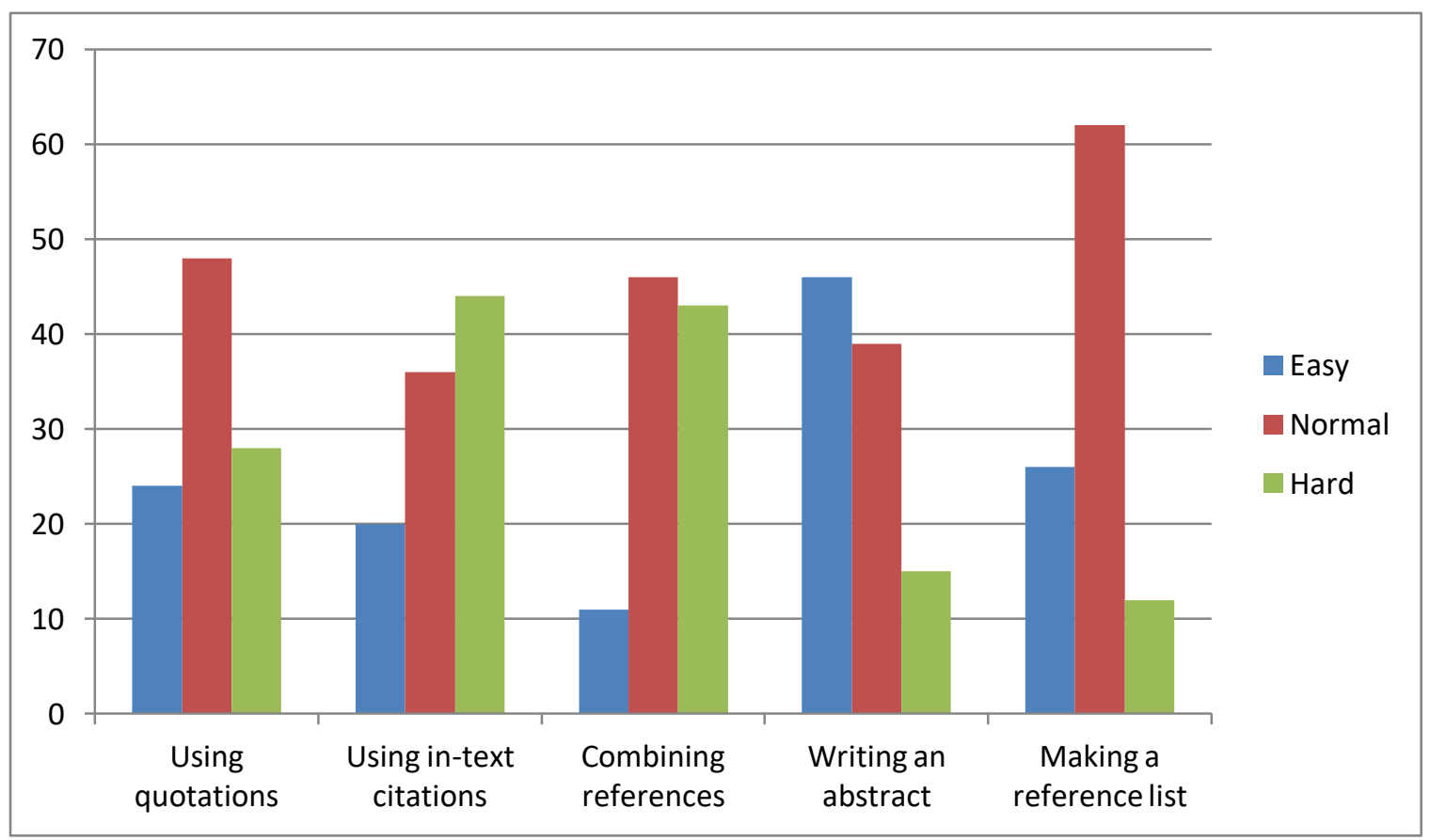

The diagram above shows that the most difficult skill for students was to use in-text citations while the easiest skill was to write an abstract. However, students have also found it relatively difficult to make a list of the references they used in their paper, use quotations and combine resources.

The second part of the questionnaire consisted of four questions that expressed students' preferences using a three point Likert scale (agree, neutral, disagree). The following diagram represents percentages of the most significant students' preferences.

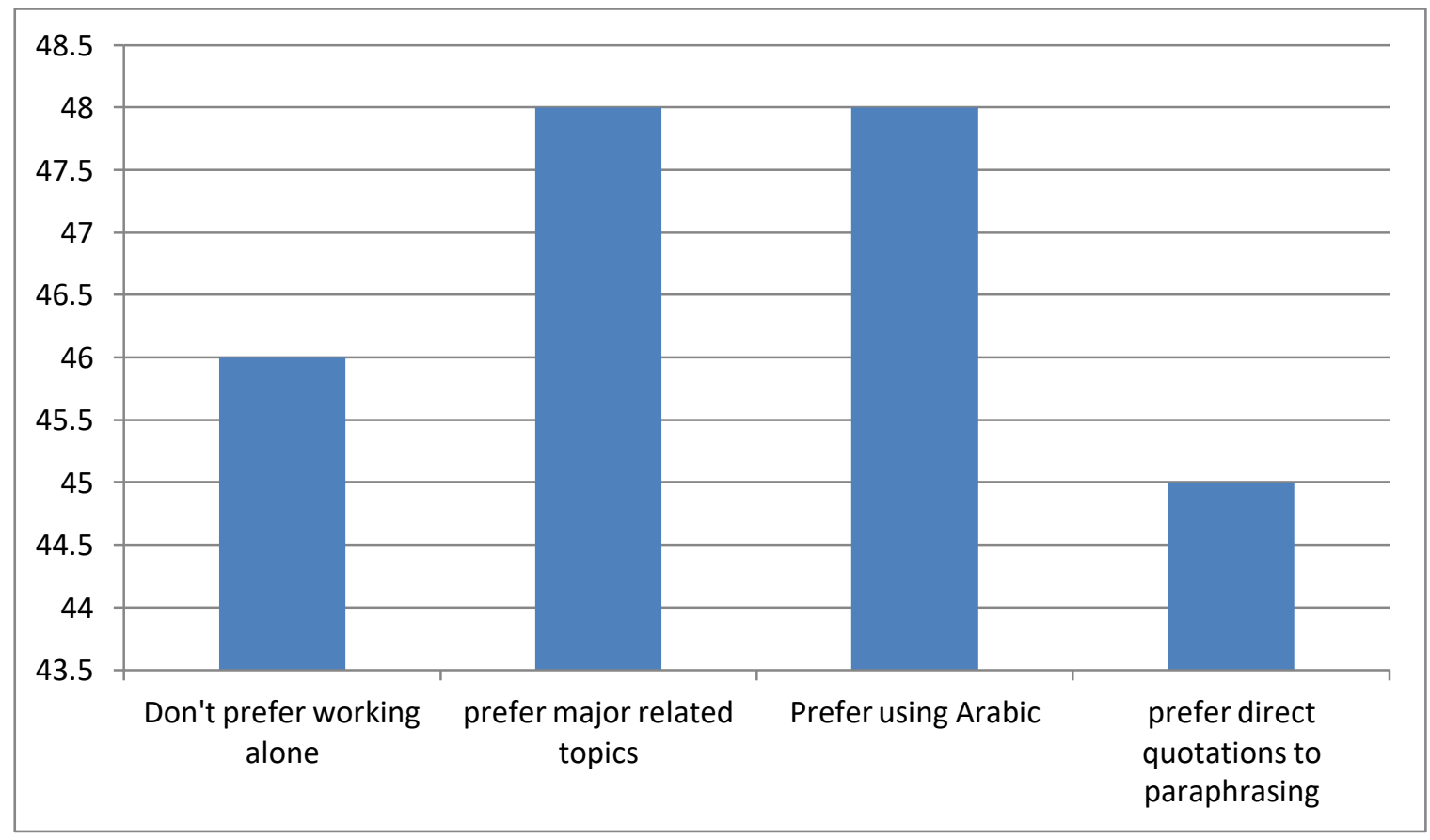


It appears that about $46 \%$ of the students do not prefer to work alone on a research paper. In addition, $48 \%$ of the students prefer working on a major related topic and using their native language for better results. However, $45 \%$ of the students stated their preference for using direct quotations over paraphrasing.

The third part of the questionnaire consisted of three statements to reveal the duration required by students for three research tasks to be completed. The following diagram exhibits the most significant percentages of the required periods of completion.

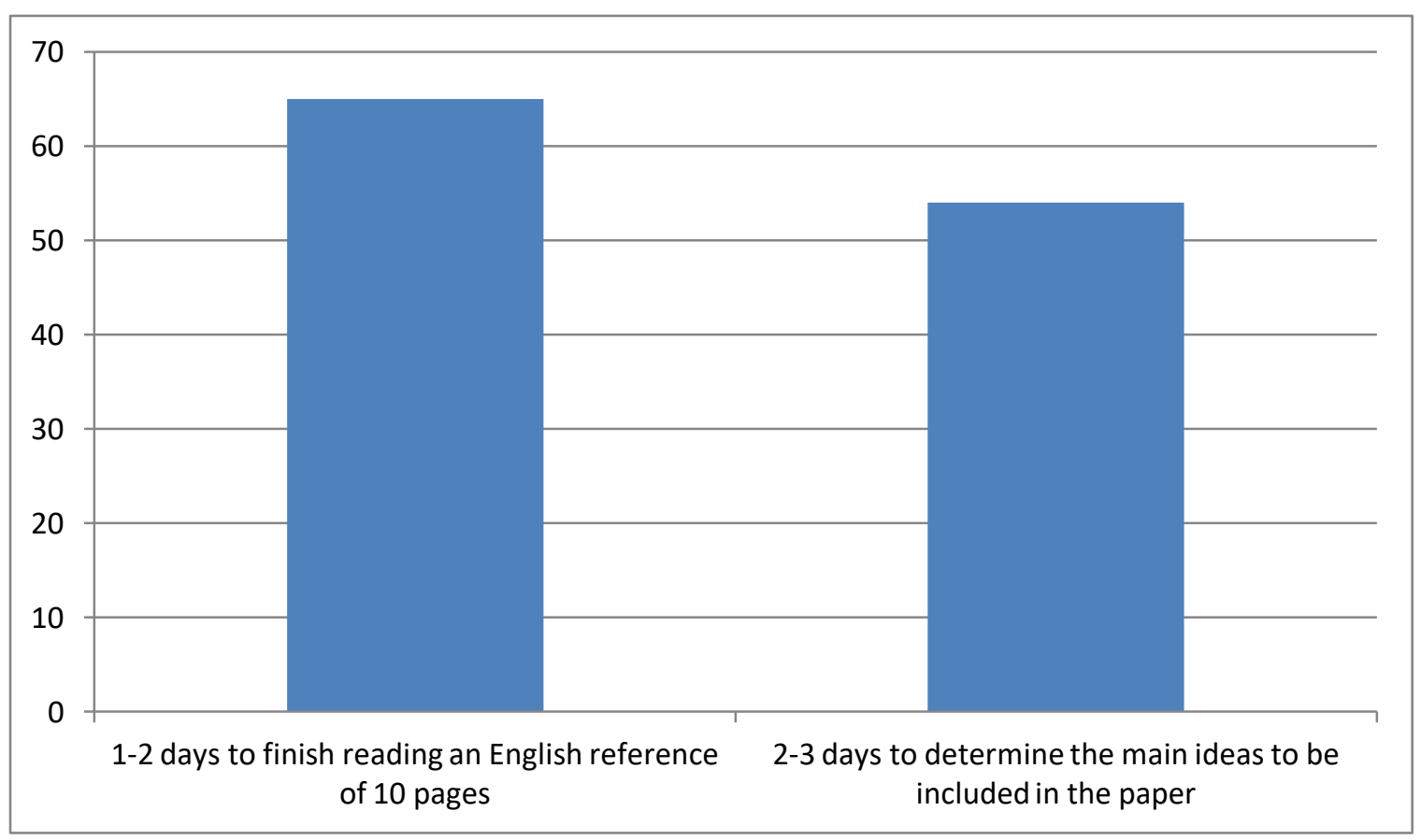

The diagram shows that $65 \%$ of the students would require about 1 or 2 days to finish reading an English reference of 10 pages. However, about $54 \%$ of the students would require 2-3 days to determine the main ideas to be discussed in their paper.

The third item in this part elicited students' statements of the required period to finish writing one paragraph of their paper. The following diagram shows that $65 \%$ of the students would require two hours to finish writing one paragraph, $25 \%$ would require one hour, and $10 \%$ would require more than two hours.

\section{Required duration for writing one paragraph}

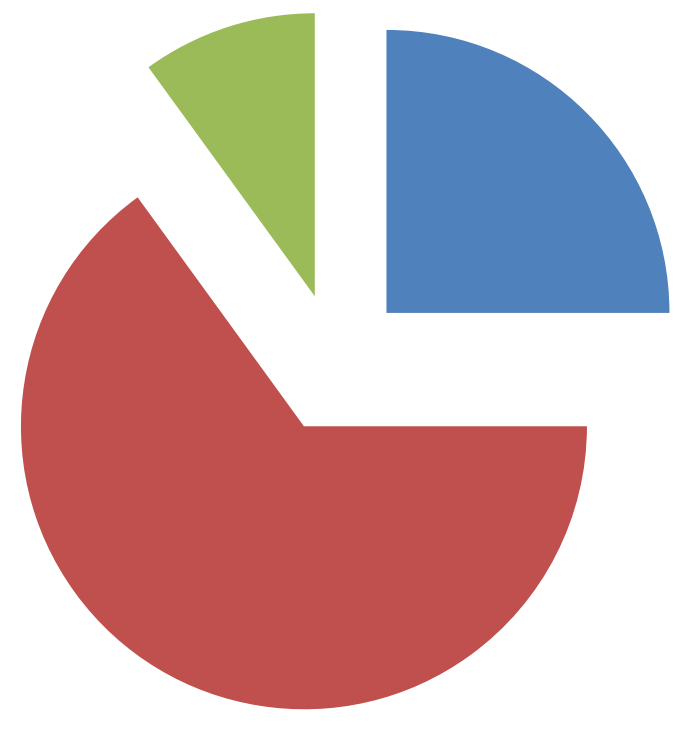

- One hour

Two hours

More than 2 hours 


\section{DISCUSSION}

\section{A. Enhancing Students' Research Skills}

After analyzing students' weaknesses and difficulties in writing research papers in English, the researcher devised a new scheme that focuses on enhancing students' research skills through dividing the work on the research paper into separate mini tasks and adopting group work for the execution. The following sections will present procedure and results.

\section{B. Group Work}

It is unquestionable that every undergraduate should be able to individually produce a complete research paper. However, offering students the chance of group work for a research paper has exhibited positive results. Students were asked to plan and divide their tasks and cooperate in difficult ones (research skills). Thus, the students were divided into groups of three members.

Evaluation:

$78 \%$ of the students exhibited high cooperativeness amongst their groups as they planned, distributed and scheduled the research tasks. They would meet twice a week for two hours to discuss, share, evaluate, and put together the pieces achieved. Group work has saved them a lot of confusion that would have resulted of going around research tasks alone. It has also saved them time and effort and made it possible for them to attend to their other courses while going through the research assignments. It has definitely granted them the opportunity to discuss, exchange, and help each other as the best learning experience is usually accomplished with the help of peers.

\section{Topic Selection}

Although students showed a preference for choosing major related topics, they did not exhibit a linguistic ability that is required to discuss such topics. Thus, the researcher has created a dozen of general topics, to pick, that allows students of mid-intermediate level of English to maneuver around.

\section{Evaluation:}

$65 \%$ of the students found it more convenient to pick a general knowledge topic for their paper. They have also exhibited high fluency while discussing the topic with their groups. They did not feel confused or in short of any specific jargon.

\section{Writing Research Questions}

The researcher asked the groups to jot several questions about what they would like to know of the topic they have chosen earlier. Then, they have to write down the final draft of these questions and show them to the researcher. In addition, the researcher advised the students to use WH questions mainly (where, when, why, how, what). The students were also advised to focus on a problem related to the selected topic. Thus, it would be more convenient to ask about the location, time, reasons, effects, and solutions of the addressed problem.

Evaluation:

$85 \%$ of the students were able to make specific inquiries about their topics represented by three or four main questions while $15 \%$ required the assistance of the researcher to form adequate questions.

\section{E. Finding Suitable Resources}

After analyzing the questionnaire's results, it was concluded that students exhibit a need for information literacy improvement. Thus, the researcher has decided to create minimized tasks with regard to finding suitable resources for student's selected topics. Students were first guided to use academic search engines that ensure getting more scholarly works. Students had to find two resources to answer each research question. It might sound that two resources would not be enough to answer each question. However, this task was mainly devised for preliminary learning and practice purposes. The students were guided through the search process that started by using a key word for the search that represent each research question. Before choosing any articles, students had to judge whether the references match the criteria of scholarly works or not. Students had to check the source that published the articles or books. It was a must that the source is either a scholarly journal, a data base, a university website or a university press. Students then were asked to check the abstracts or summaries of the list of their search results in order to find a match that can answer their research questions.

Evaluation:

$\overline{\text { About } 91 \%}$ of the students were successful in using academic search engines. However, only $68 \%$ were able to find and judge references to answer their research questions.

\section{F. Paraphrasing and Summarizing}

During this research, students were not asked to write or submit a complete paper. Never the less, they were asked to choose two paragraphs from each selected article that answer directly each of the research questions. Then, students were guided through steps of proper paraphrasing and summarizing. These included reading, underlining the main ideas and key words, taking notes, replacing some words with their synonyms, and rewriting phrases using different 
structures. After doing a model exercise, the students had to paraphrase one paragraph and summarize another from each of the selected paragraphs.

Evaluation:

The students succeed in paraphrasing their paragraphs but needed more practice to master summarizing. This is because most students were not able to limit their summaries and present the main ideas in a brief structure.

\section{G. Using Quotations and In-text Citations}

By means of examples, students were introduced to direct, indirect, short, and block quotations. Then, students were asked to make different kinds of quotations using one paragraph of each selected article. Following that, students were familiarized with different sets of in-text citation that differ according to the number of authors contributing to the original cited work. Eventually, students were asked to cite the quotations they formed in the previous exercise.

Evaluation;

$84 \%$ of the students were able to successfully use quotations and proper in-text citation. This was a quite surprising result as a good percentage of students has expressed in the questionnaire conducted earlier a difficulty in quoting and citing.

\section{CONCLUSION}

It is evident throughout the paper that with proper planning and guidance, educators could make their students capable of handling research tasks as part of their preparation of research papers in English. In addition, breaking the preparation process into mini tasks and encouraging team work and peer consultation would guarantee successful above average research papers.

\section{REFERENCES}

[1] Andone, D., Dron, J., Pemberton, L., \& Boyne, C. (2007). E-learning environments for digitally-minded students. Journal of Interactive Learning Research, 18(1), 41-53.

[2] Barnard, L., Lan, W. Y., To, Y. M., Paton, V. O., \& Lai, S.-L. (2009). Measuring Self Regulation in Online and Blended Learning Environments. Internet and Higher Education, 12(1), 1-6.

[3] Berkenkotter, C., Huckin, T., \& Ackerman, J. (1991). Social context and socially constructed texts: The initiation of a graduate student into a writing research community. In C. Bazerman \& J. Paradis (Eds.), Textual dynamics of the professions (pp.191215). Madison, Wisconsin: The University of Wisconsin Press.

[4] Brown, C. A., \& Dickson, R. (2010). Healthcare students' e-literacy skills. Journal of Allied Health, 39(3), 179-184.

[5] Bruce, B., \& Peyton, J. K. (1990). A New Writing Environment and an Old Culture: A Situated Evaluation of Computer Networking to Teach Writing. Interactive Learning Environments, 1(3), 171-191.

[6] Bruce, C. (1997). The seven faces of information literacy. Adelaide: Auslib Press.

[7] Egberongbe, H.S. (2011). The use and impact of electronic resources at the University of Lagos. Library Philosophy and Practice. Retrieved from: http://www.webpages.uidaho.edu/ mbolin/egberongbe.htm

[8] Collins, A., Joseph, D., \& Beilaczyc, K. (2004). Design research: Theoretical and methodological issues. The Journal of Learning Sciences, 13(1), 15-42.

[9] Day, K., \& Wells, S. (2009, 6-9 December 2009). Adapting social media for scaffolding for health informatics learning. Paper presented at the ASCILITE Conference, Auckland, New Zealand.

[10] Dirckinck-Holmfeld, L. and Lorentsen, A. (2003). 'Transforming university practice through ICT-integrated perspectives on organizational, technological, and pedagogical change', Interactive Learning Environments, Vol. 11, No. 2, pp.91-111

[11] Dodge, B. (1995). WebQuests: A technique for internet-based learning. Distance Educator, 1(2), 10-13.

[12] Doering, A. (2007). Adventure Learning: Situating Learning in an Authentic Context. SO - Innovate: Journal of Online Education, 3(6), 40-49.

[13] Drury, H., \& Webb, C. (1991). Literacy at tertiary level: Making explicit the writing requirements of a new culture. Paper presented at the Inaugural Systematic Linguistics Conference, Deakin University.

[14] Freedman, A. (1987). Learning to write again: Discipline specific writing at university. Carleton Papers in Applied Language Studies, 4, 45-65.

[15] Gonzales, C. (2010). What do university teachers think eLearning is good for in their teaching? Studies in Higher Education, $35(1), 61-78$.

[16] Hannon, J. (2009). Breaking down online teaching: Innovation and resistance. Australasian Journal of Educational Technology, 25(1), 14-29.

[17] Hazel, P. (2008). Toward a Narrative Pedagogy for Interactive Learning Environments. Interactive Learning Environments, $16(3), 199-213$.

[18] Herrington, J., \& Oliver, R. (2000). An instructional design framework for authentic learning environments. Educational Technology Research \& Development, 48(3), 23-48.

[19] Hess, C. (2002). Score and word: Writing about music. In M. Natvig (Ed.), Teaching music history (pp. 193-204). Aldershot: Ashgate.

[20] Hutchins, E. (2000). Distributed Cognition. Retrieved August 2, 2011 from IESBS Distributed.

[21] Holt, D., Smissen, I., \& Segrave, S. (2006). New students, new learning, new environments in higher education: Literacies in the digital age. Paper presented at the 23rd annual ascilite conference: Who's learning? Whose technology?, The University of Sydney. 
[22] Hull, D. M., \& Saxon, T. F. (2009). Negotiation of Meaning and Co-Construction of Knowledge: An Experimental Analysis of Asynchronous Online Instruction. Computers and Education, 52(3), 624-639.

[23] Ikpeze, C. H., \& Boyd, F. B. Web-based inquiry learning: Facilitating thoughtful literacy with WebQuests. The Reading Teacher, 60(7), 664-654.

[24] Lave, J., \& Wenger, E. (1991). Situated Learning. Legitimate peripheral participation. Cambridge: Cambridge University Press.

[25] Leu, D. J., Kinzer, C. K., Coiro, J. L., \& Cammack, D. W. (2004). Toward a theory of new literacies emerging from the Internet and other information and communication technologies. In R. B. Ruddell \& N. J. Unrau (Eds.), Theoretical models and processes of reading. 5th Edition (pp. 1570-1613). Newark, ED: International Reading Association.

[26] March, T. (1995). What's on the Web: sorting strands of the World Wide Web for educators. Computer's-using Educators Newsletter Retrieved 17 June 2011, from <http://www.ozline.com/learning/webtypes.html>.

[27] March, T. (2003-2004). The learning power of WebQuests. Educational Leadership, 61(4), 42-47.

[28] Norman, C. D., \& Skinner, H. A. (2006). eHealth Literacy: Essential Skills for Consumer Health in a Networked World. Journal of Medical Internet Research, 8(2), 30-33.

[29] November, N. (2010). Integrating online group work into first-year music studies in New Zealand: 'This IS a University'. In A. Ragusa (Ed.), Interaction in Communication Technologies and Virtual Learning Environments: Human Factors (pp. 314-330). Hershey, PA: Information Science Reference.

[30] Orr, M., \& Day, K. (2004). Knowledge and learning in 'successful' IT projects: a case study. Health Care and Informatics Review Online, (17/06/2004). Retrieved from <http://www.enigma.co.nz/hcro/website/index.cfm?fuseaction=articledisplay\&Feature>

[31] Pope, R. (1995). Textual intervention: Critical and creative strategies for literary studies: Routledge. Milton park, Abingdon.

[32] Prensky, M. (2001). Digital natives, digital immigrants. On the Horizon, 9(5), 34-40.

[33] Reed, P., Smith, B., \& Sherratt, C. (2008). 'A New Age of Constructivism: 'Mode Neutral'. E-Learning 5(3), pp: 310-322

[34] Reeves, T., Herrington, J., \& Oliver, R. (2005). Design research: A socially responsible approach to instructional technology research in higher education. Journal of Computing in Higher Education, 16(2), 97-116.

[35] Reeves, T., McKenny, S., \& Herrington, J. (2010). Publishing and perishing: The critical importance of educational design research. Paper presented at the 27th annual ascilite conference: Curriculum, technology and transformation for an unknown future, Sydney.

[36] Richardson, L. (2003). Writing: A method of inquiry. In N. K. Denzin \& Y. S. Lincoln (Eds.), Collecting and Interpreting Qualitative Materials (pp. 499 - 541). Thousand Oaks: Sage Publications.

[37] Ridgeway, V. G., Peters, C. L., \& Tracy, T. S. (2002). Out of this world: Cyberspace, literacy and learning. In C. C. Block, L. B. Gambrell \& M. Pressley (Eds.), Improving comprehension instruction: Rethinking research, theory and classroom practice (pp. 290-307). San Francisco: Jossey-Bass.

[38] Ross Adkins, N., \& Corus, C. (2009). Health literacy for improved health outcomes: Effective capital in the marketplace. Journal of Consumer Affairs, 43(2), 199 - 222.

[39] Sharma, P., \& Hannafin, M. J. (2007). Scaffolding in Technology-Enhanced Learning Environments. Interactive Learning Environments, 15(1), 27-46.

[40] Tapscott, R. (1998). Growing up digital: The rise of the Net Generation. New York: McGraw-Hill.

[41] Tardy, C. (2005). 'It's like a story': Rhetorical knowledge development in advanced academic literacy. Journal of English for Academic Purposes, 4, 325-338.

[42] Taylor, T., \& Young, C. (2003). Making history: A guide for the teaching and learning of history in Australian schools. Retrieved 26 June 2011, from <http://www.hyperhistory.org/index.php?option=displaypage\&Itemid=607\&op=page>

[43] Teo, T. (2006). Attitudes toward Computers: A Study of Post-Secondary Students in Singapore. Interactive Learning Environments, 14(1), 17-24. The University of Auckland. (2011). General Education. Retrieved 10 April, 2011, from <http://www.auckland.ac.nz/uoa/cs-general-education>.

[44] Vygotsky, L. S. (1978). Mind in Society: The development of higher psychological processes. Cambridge, MA: Harvard University Press.

[45] Warnock, S. (2009). Teaching writing online: How and why. Urbana, IL: National Council of Teachers of English.

[46] Wenger, E. C. (1998). Communities of Practice: Learning, Meaning, and Identity. New York; Cambridge: Cambridge University Press.

[47] Woodward-Kron, R. (2004). 'Discourse communities; and 'writing apprenticeship': An investigation of these concepts in undergraduate Education students' writing. Journal of English for Academic Purposes, 3, 139-161.

Ranwa Khorsheed, born in Damascus, Syria, June, 1984. Studied English language and literature at Damascus University. Got a Master degree in general linguistics, Damascus University, 2014. She worked for private language institutes. Also worked as an English language instructor at Damascus University. (2015-Present) working for the Syrian Virtual University and the Arab international University in Damascus, Syria. Published several papers on language teaching and co-authored a book on academic writing and research. 